
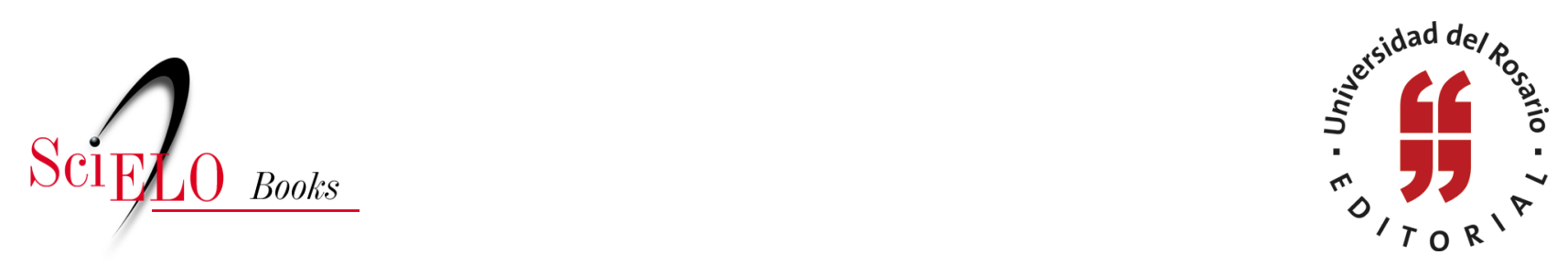

\title{
5. Análisis político sobre la emergencia de los estudios de clientelismo
}

\author{
Laura Daniela Guerrero García
}

\section{SciELO Books / SciELO Livros / SciELO Libros}

GUERRERO GARCÍA, L.D. Análisis político sobre la emergencia de los estudios de clientelismo. In: Clientelismo político, ¿desviación de la política o forma de representación?: Estado del arte sobre las aproximaciones al clientelismo en Colombia 1973-2011 [online]. Bogotá: Editorial Universidad del Rosario, 2014, pp. 67-78. Opera prima collection. ISBN: 978-958-738-552-6. https://doi.org/10.7476/9789587385526.0007.

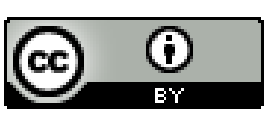

All the contents of this work, except where otherwise noted, is licensed under a Creative Commons Attribution 4.0 International license.

Todo o conteúdo deste trabalho, exceto quando houver ressalva, é publicado sob a licença Creative Commons Atribição 4.0.

Todo el contenido de esta obra, excepto donde se indique lo contrario, está bajo licencia de la licencia $\underline{\text { Creative }}$ Commons Reconocimento 4.0 . 


\section{Análisis político sobre la emergencia de los estudios de clientelismo}

Los estudios sobre clientelismo en Colombia no han estado desarticulados del contexto histórico-político del país. La puesta en escena de este fenómeno como unidad de análisis y su respectiva problematización, desde diversos enfoques, da cuenta e interactúa, también, con luchas políticas e ideológicas vivenciadas en las últimas décadas. No es de interés del presente trabajo realizar un análisis de corte historiográfico sobre la política nacional desde la segunda mitad del siglo xx, pero sí presentar aquellos eventos diagnósticos que ayudan a comprender el contexto en el cual se producen los estudios del clientelismo en Colombia. ${ }^{96} \mathrm{El}$ presente capítulo trabajará cuatro eventos diagnósticos: i) el período del Frente Nacional (1958-1974); ii) el desmonte del citado régimen y la consecuente crisis del bipartidismo; iii) la reforma política de 1968; y iv) la Constitución política de 1991.

\footnotetext{
${ }^{96}$ Estas coyunturas son una suerte de eventos diagnósticos. Se entiende por estos eventos aquellos momentos históricos que "revelan tanto competencias, contradicciones y conflictos que están sucediendo como los esfuerzos para prevenirlos, suprimirlos o reprimirlos". Ver María Clemencia Ramírez, Entre el Estado y la guerrilla: identidad y ciudadanía en el movimiento de los campesinos cocaleros en Putumayo (Bogotá: Instituto Colombiano de Antropología e Historia-Colciencias, 2001), 20.
} 


\subsection{Frente Nacional}

Los partidos tradicionales cumplen un papel fundamental en la historia y devenir político de Colombia desde el siglo xix. De acuerdo con Fernán González, cuando el Estado colombiano no tenía presencia, ni control, sobre la totalidad de su territorio, los partidos se encargaron de crear identidades más allá de las locales o regionales e integrar las clases populares a la vida política nacional, a través de las clientelas. Esta inclusión vertical desde arriba fue un modo para superar la fragmentación del territorio colombiano y posibilitar que algunos intereses regionales fueran agenciados por la burocracia central, superando, en parte, problemas de indiferencia $\mathrm{y}$ frialdad de la tecnocracia nacional con respecto a las demandas y reivindicaciones locales.

En aquel entonces, para González, la inclusión de las clientelas en la política nacional no representaba una amenaza para la estabilidad del régimen político. Por el contrario, este mecanismo permitió la legitimación electoral de los partidos y de los gobiernos posteriores. ${ }^{97}$

Ahora bien, la escasez de bienes públicos y la precariedad estatal en lo local fomentaron la competencia interpartidista por el acceso a los recursos públicos y el mantenimiento de las redes clientelares. En este contexto, la inscripción y adhesión partidista era un asunto vital en las regiones, pues generaba sentido de pertenencia, proveía identidad política y aseguraba el acceso a bienes y servicios públicos limitados. No en vano, los partidos Conservador y Liberal se comportaron como intransigentes subculturas que imposibilitaron la creación de un proyecto nacional

${ }^{97}$ Comparar González, ‘CColapso?”, 137. 
unificado, pese a que lograron trascender en ocasiones las fronteras regionales. ${ }^{98}$

El bipartidismo imprimió, desde entonces, unas características que diferencian el sistema político colombiano de otros sistemas en el continente. Según David Roll, en Colombia existen mecanismos de mediación clientelista, enraizados en los partidos tradicionales, junto con un modelo de democracia formal, restringida y excluyente. Esta combinación le imprime al régimen un rasgo de estabilidad y continuismo en contraste con otros países latinoamericanos. ${ }^{99}$ No en vano, Colombia fue uno de los pocos países sin dictaduras de largo alcance y sin movimientos populistas de gran envergadura. ${ }^{100}$ Daniel Pecaut, por su parte, observa que el clientelismo colombiano se configuró como un mecanismo de asociación política que imposibilitó la existencia de populismos, la creación de un proyecto nacional y la búsqueda de soluciones para los problemas sociales que enfrentaba la violencia rural y urbana. ${ }^{101}$ Marco Palacios refuerza esta idea señalando que el fracaso de movimientos populistas de ideología de izquierda en Colombia, tales como el gaitanismo y el anapismo, no se explica por la intervención de unas fuerzas armadas, sino por el funcionamiento del

${ }^{98}$ Comparar Roll, Rojo, 57.

${ }^{99}$ Comparar Roll, Rojo, 57.

${ }^{100} \mathrm{El}$ único gobierno colombiano considerado bajo el título de dictadura fue el de Gustavo Rojas Pinilla, el cual tuvo lugar de 1953 a 1957, para luego ser remplazado por una junta militar de un año, instaurada para la transición a la democracia. Esta dictadura fue la base para la construcción del régimen de coalición denominado Frente Nacional. Se dice que Colombia no presentó dictaduras de largo alcance, puesto que esta excepcionalmente corta dictadura no es comparable con otros regímenes militares del continente.

${ }^{101}$ Comparar Daniel Pecaut, "Populismo imposible y Violencia: El caso colombiano", en Guerra contra la sociedad (Bogotá: Editorial Planeta Colombiano, 2001), 53- 86. 
sistema político bipartidista. ${ }^{102}$ Es decir, el clientelismo imprimió en el país unos rasgos particulares que marcaron una diferencia de la vida política nacional con respecto a otros procesos políticos latinoamericanos, evitando los caudillismos o las dictaduras militares que marcaron su historia.

En la década de 1930 a 1940, el país entró en un proceso de modernización económica donde los partidos políticos tradicionales pasaron a ser canales de captación de masas que terminaron por producir un equilibrio. Sin embargo, la intransigencia de sus dirigentes e ideólogos terminó por conducir al país a una guerra entre las subculturas políticas que dio origen al período histórico conocido como la Violencia en Colombia. ${ }^{103}$

El cierre de este período, paradójicamente, se da a partir de pacto suscrito por las élites políticas liberales y conservadoras para poner fin a su enfrentamiento. La fórmula acordada inaugura el período del Frente Nacional en el país (1958-1974). Sobre el tema, David Roll anota que le siguió a "la reanudación de la violencia y esa utópica ambición de Rojas Pinilla de sustituir un bipartidismo pujante y conflictivo". ${ }^{104}$ Sin embargo, paradójicamente, esa misma capacidad de movilización ciudadana que habían tenido los partidos fue la misma que luego se vio socavada cuando el Acto Legislativo Numero 1 de 1959 consagró la alternancia presidencial. ${ }^{105}$ De esta manera, se pactaron, sin consultar al constituyente primario, los principios de alternancia y paridad

${ }^{102}$ Comparar Marco Palacios, "Presencia y ausencia de populismo: para un contrapunteo colombo-venezolano”, en Populistas, mandarinesy violencias. Luchas por el poder (Bogotá: Editorial Planeta Colombiano, 2001), 45-81.

${ }^{103}$ Comparar también Roll, Rojo; Jaime Arocha Rodríguez, “Clientelismo, gasteo y violencia”, Enfoques colombianos, (1980); Archer, The Transition; Martz, The Politics.

${ }^{104}$ Ver Roll, Rojo, 57.

${ }^{105}$ Ibid., 58. 
política entre los dos partidos tradicionales. Estas reglas del juego determinaron formalmente la vida política del país durante los siguientes 16 años. ${ }^{106}$

Pronto, la repartición burocrática terminó por desideologizar a los partidos. El régimen del Frente Nacional no sólo evidenció su incapacidad para crear programas competitivos, sino también, para buscar mecanismos de inclusión de nuevos sectores, por supuesto más amplios que los meros clientelares. ${ }^{107}$ Implicó, por tanto, la pérdida de la capacidad de cooptación y arrastre electoral de los partidos tradicionales y evidenció el carácter restringido de sus clientelas y la incapacidad e inconsistencia para generar un proyecto democrático que superara las coyunturas electorales.

Para John D. Martz, Colombia adoptó un sistema político excluyente e implantó estructuras formales que se ajustaban a la definición ortodoxa de democracia, pero con un pluralismo restringido, una predominancia del ejecutivo, un estilo patrimonial de regulación y una ausencia marcada de ideologías. ${ }^{108}$

\subsection{Crisis del bipartidismo}

La noción de crisis alude a dos fenómenos independientes, pero estrechamente interconectados: i) la crisis de los partidos tradicionales que estalló, con fuerza, en la década de los ochenta y ii) la pérdida de legitimidad del sistema político, en su conjunto, derivada en buena parte del Frente Nacional. Vale recordar que los partidos

${ }^{106}$ Comparar Jonathan Hartlyn, La politica del régimen de coalición (Bogotá: Tercer Mundo y Universidad de los Andes, 1993). Quizás se trata del estudio más sistemático sobre el Frente Nacional y, aunque hace referencia al clientelismo como fenómeno histórico, no parece ser una preocupación central del autor.

${ }^{107}$ Comparar Roll, Rojo, 75.

${ }^{108}$ Comparar Martz, The Politics, 38. 
tradicionales se convirtieron en los protagonistas exclusivos de la historia política y, por tanto, la alteración de los mismos repercutía en el sistema político en general. ${ }^{109}$

Los partidos no entraron a la modernización política ni se sintonizaron con las transformaciones culturales y la modernización económica que vivió el país en las seis primeras décadas del siglo xx. ${ }^{110}$ Ellos se acostumbraron a reproducirse a través del mecanismo de inclusión vertical. La alternancia del poder y la minuciosa repartición burocrática del Frente Nacional les aseguraba un espacio para sus clientelas. Sin embargo, esta fórmula no daba respuesta a los malestares y demandas de vastos sectores urbanos, que empezaban a hacer presencia en la esfera pública del país. ${ }^{111}$ Pronto se observó que sólo los ciudadanos con intereses de por medio acudían a las urnas. En consecuencia, el clientelismo y el uso de los recursos estatales rápidamente se esgrimieron como las modalidades empleadas por los partidos para la recuperación del control político. Sus esquemas clientelistas aseguraban la continuidad en el poder político y, simultáneamente, acrecentaba la distancia con las demandas políticas del país emergente. El vacío de representación pudo haber sido un detonador de la apatía y el abstencionismo, así como de la opción de la vía armada como mecanismo para propiciar cambios en el sistema político.

La no sintonía del país político con los cambios que demandaba el país real se acrecentaba aún más en el escenario legislativo. Las iniciativas transformadoras y otras se veían truncadas debido a que todas ellas requerían de mayoría calificada y no simple. Este modo de elección se instauró en el Frente Nacional con el

\footnotetext{
${ }^{109}$ Comparar Roll, Rojo, 57.

${ }^{110}$ Comparar Jaramillo, Clientelismo y poder: relectura, 29.

${ }^{111}$ Comparar Roll, Rojo, 56.
} 
objetivo de evitar conflictos bipartidistas. Sin embargo, la medida pronto se tradujo en una situación sostenida de ingobernabilidad.

\subsection{Modernización y reforma del 68}

La idea de cambiar el sistema fue capitalizada por el presidente liberal Carlos Lleras Restrepo (1966-1970). A pesar de las trabas del legislativo, se logró impulsar la reforma constitucional de 1968. La reforma perseguía la modernización del país. Para tal efecto, se buscó fortalecer la orientación del ejecutivo, previo proceso tecnocrático de planeación, en detrimento del poder legislativo. ${ }^{112} \mathrm{Sin}$ embargo, su aprobación no fue fácil: esta se surtió de una fuerte oposición por parte de los parlamentarios. ${ }^{113}$ Por ende, para su trámite exitoso se les concedieron privilegios que les aseguraran las curules y el acceso a bienes públicos vía mecanismos clientelares. ${ }^{114}$ Así, la reforma aseguró la reproducción de redes clientelistas vía la creación de los llamados auxilios parlamentarios, ${ }^{115}$ los cuales financiaron campañas reeleccionistas de los congresistas y el mantenimiento de redes clientelares. ${ }^{116}$

La reforma del 68, además, permitió dar continuidad a la fórmula de partición proporcional. ${ }^{117} \mathrm{Y}$ si bien esta generó cambios de gran envergadura en el régimen constitucional anterior, también marcó el comienzo de una forma de operación particular del

${ }^{112}$ Comparar González, “Clientelismo”, 85.

${ }^{113}$ Ibid., 85.

${ }^{114}$ Comparar Roll, Inestabilidad,18-19.

${ }^{115}$ Partidas presupuestales para el desarrollo de proyectos que solucionaran problemáticas, necesidades y demandas de cada una de las circunscripciones electorales, pero cuyo gasto era discrecional de los congresistas

${ }^{116}$ Comparar Martz, The Politics, 291.

${ }^{117}$ Comparar Roll, Inestabilidad, 301. 
Congreso. Por ende, en este contexto, no se logró una plena modernización del régimen político y, por el contrario, se afianzó el clientelismo como modo de operación del sistema político. Sus resultados enquistaron unas élites políticas y económicas lejanas a la ciudadanía, que en general desconfiaban de los políticos y no se sentían representadas por los partidos. La crisis de legitimidad del régimen político era cada vez más evidente.

Por otra parte, la reforma del 68 generó una división (discursiva) de la clase política nacional. La división liberales versus conservadores cedió el terreno a la realizada entre políticos tecnócratas, asociados al país económico, la rama ejecutiva del poder público y el discurso modernizante de la política, versus políticos clientelistas, asociados al bipartidismo de corte rural, regional y a la rama legislativa con tonos más arcaicos en el quehacer político. No en vano, en aquel entonces, los integrantes de la Comisión del Plan en el Congreso tildaban de clientelistas a sus opositores. ${ }^{118}$ En este orden discursivo, los cuerpos colegiados pronto pasaron a ser considerados como el principal impedimento para el desarrollo del país. De esta manera, el clientelismo emerge como un mecanismo de reproche mutuo entre partidos, al igual que un objeto visible y de gran envergadura del sistema político colombiano.

Según Martz, no se puede desconocer que mientras el Frente Nacional estuvo vigente, este procuró la estabilización de la democracia en su sentido formal. Sin embargo, los aspectos rescatables del pacto no fueron suficientes para superar los aspectos indeseables del mismo. En consecuencia, en 1968 se inició el proceso de su desmonte ${ }^{119}$ con el fin de desvincular la participación de los

118 Comparar Alfonso Miranda Talero, "Del manzanillismo al clientelismo presupuestal", Areopago, 2 (1987): 24.

${ }^{119}$ Comparar Martz, The Politics, 36. 
partidos políticos de la toma de las decisiones estatales. ${ }^{120}$ Aun cuando el desmonte se inició en 1968, muchas de las dinámicas establecidas durante este pacto se perpetuaron de facto hasta la década de los ochenta.

\subsection{Constitución de 1991}

El discurso anti-clientelista, el de la paz y el de una democracia efectiva fueron el motor para adelantar las reformas políticas de finales de los años ochenta y principio de los años noventa (reforma constitucional de 1986 y Constitución política de 1991). Si bien Colombia no había vivido una dictadura instaurada por un largo periodo de tiempo, sí se hablaba en aquel entonces de una democracia más formal que real, excluyente y restringida. Para entender la magnitud del fenómeno es fundamental saber cómo funcionaba el sistema antes de 1991. Para lo cual, Rodrigo Losada señala:

[...] es conviene recordar cuál era la práctica anterior a 1991: el candidato al Senado hacía alianzas con uno o más candidatos a Cámara, y a través de éstas, o él directamente, pactaba también alianzas con uno o más candidatos a Asamblea y con uno o más candidatos a Concejos en varios municipios del departamento. Se conformaban pirámides de alianzas, en las que todos los integrantes se fortalecían, o esperaban lograrlo. De hecho, quienes más se beneficiaban de estas alianzas eran quienes las coronaban, o sea, los grandes caciques regionales. ${ }^{121}$

${ }^{120}$ Ibid., 309.

${ }^{121}$ Rodrigo Losada, "Reformas regresivas: las reformas electorales propuestas por el gobierno solo favorecen a los caciques y al clientelismo", Dinero, septiembre, 1996. Este artículo es importante en la medida en que muestra cuáles fueron los puntos de discusión a 
La Constitución de 1991 consagró reformas electorales que tenían como objetivo romper con la estructura piramidal y clientelista anteriormente descrita. El resultado inesperado de las mismas fue un aumento del abstencionismo, la aparición del voto de opinión y, consecuentemente, la reducción aparente del voto clientelista. $\mathrm{Si}$ bien la nueva carta política eliminó las bases de grandes caciques regionales, también dio origen a pequeñas redes locales con capacidad limitada de movilización de recursos, mejor conocidas como micro-empresas. ${ }^{122}$ Esta ruptura con la estructura piramidal clientelista es lo que ha sido denominado el colapso de la maquinaria política. ${ }^{123}$

La entrada en vigencia de la Constitución política de 1991, en Colombia, generó limitación a las prácticas clientelistas de los políticos tradicionales, gracias a medidas tales como: i) la eliminación de los auxilios parlamentarios; ii) la aparición del tarjetón en sustitución de la papeleta y iii) el control sobre los recursos manejados discrecionalmente por los políticos. Esto, si bien tenía como objetivo erradicar el clientelismo, antes que hacerlo de raíz,

propósito de la reforma electoral. Lo más importante es que el autor permite identificar que las teorías democráticas propuestas por autores como Robert Dahl y Giovanni Sartori son contradictorias con las prácticas políticas tradicionales en Colombia. Dentro de los temas de coyuntura del momento se encuentran: el voto obligatorio, la unificación del calendario electoral y la prolongación del periodo de las autoridades electivas electorales regionales.

122 "Las micro-empresas electorales son la expresión en el plano electoral de las facciones personalistas que, en su sumatoria de representaciones fragmentadas, conforman un conjunto heterogéneo que todavía se llama partido (Liberal o Conservador, con mayúsculas). También son el instrumento de expresión electoral de múltiples movimientos o micro-partidos no adscritos a los partidos tradicionales para ingresar al juego político-electoral". Ver Pizarro Leongómez, "La atomización”, 357.

${ }^{123}$ Comparar también Santos Villagrán, "Bogotá”, 13. 
suscitó la trasformación del fenómeno, pasando del anterior clientelismo corporativo (moderno) a uno más de tipo de mercado. ${ }^{124}$

La reforma no eliminó las prácticas clientelistas. Por el contrario, lo que se presenció fue una adaptación de las mismas a las nuevas realidades institucionales. A manera de ejemplo, los auxilios parlamentarios pronto fueron remplazados por los fondos de cofinanciación, figura que fue utilizada por el ejecutivo como un mecanismo para dar prebendas al legislativo a cambio de votos favorables a sus iniciativas. ${ }^{125}$

El recorrido por el contexto político permite esgrimir a manera de hipótesis de trabajo que el clientelismo (en sus diferentes modalidades: tradicional, moderno o de mercado) ha estado estrechamente articulado con el sistema político colombiano. Este fenómeno se ha alimentado del sistema y en su desarrollo le ha generado improntas significativas, que lo caracterizan y particularizan. La relación del clientelismo y el bipartidismo, en el marco de una democracia formal, pero excluyente, es notoria. En este contexto, el clientelismo toma rasgos de fenómenos como el caciquismo y patronazgo, pero no se reduce a estos. Por el contrario, se observa que el clientelismo cumplió una función de articulación de lo local y lo nacional a través del régimen bipartidista, evitando la diferenciación de los proyectos políticos y perpetuando subculturas que no lograron sintonizarse con los procesos de modernización demandados; de manera opuesta, los partidos tradicionales terminaron generando lo que se conoce como la Violencia Política. La superación de este período se dio mediante un pacto y arreglo institucional que le dio más oxígeno y vida al clientelismo político

${ }^{124}$ Comparar también Gutiérrez, “Clientelismo y sus enredos”; Dávila Ladrón de Guevara, “Clientelismo, intermediación”, 62-78.

${ }^{125}$ Comparar Roll, Rojo, 73. 
en Colombia. El desmonte del Frente Nacional implicó no sólo superar la división antagónica entre los partidos Liberal y Conservador, sino también trajo consigo una nueva división entre políticos técnicos, modernizantes y próvidos para lo público versus políticos clientelistas, atávicos y con tintes de corruptos. Emerge, entonces, un discurso anti-clientelista que influenciaría muchos de los estudios producidos a lo largo de los años ochenta e, incluso, la reforma constitucional de 1991. Es por ello que, antes de 1991, los estudios sobre clientelismo presentan un visión preeminentemente negativa del mismo. Sin embargo, la adaptación del fenómeno a las nuevas realidades constitucionales, permite inferir que el sector autodefinido como no-clientelista no estaba exento de utilizar prácticas similares. Por lo anterior, cualquier reforma institucional que busque la eliminación del fenómeno, antes que dar muerte al mismo, parece generar su trasformación y rápida adaptación a las nuevas reglas. 